\title{
Internationalisation as a Lever for Change: The Case of Italy
}

\author{
Fiona Hunter
}

\section{Introduction}

The many changes introduced over the previous decade in Europe by the Bologna Process have called for new state-university relations and behaviours, as well as new understandings and enactments of internationalization. However, how this has been interpreted by national higher education policies has depended significantly on the different country contexts (Nokkala 2007). Italy represents a national system that has struggled to introduce effective Bologna reforms because of an unfavourable starting point: in the preceding decades, it failed to cope with the challenges of a changing higher education environment and with the explosion of demand for higher education (Van der Wende 2001).

This has had consequences for its higher education institutions operating in a resource dependency regime (Marginson 2007; Pfeffer and Salancik 1978). Although only the 66 state universities in the Italian higher education system ${ }^{1}$ rely heavily on state funding, all 95 (including the 29 non-state universities who are essentially privately funded) are regulated by the Ministry for Education, Universities and Research (MIUR). If the national system, caught up in its own path dependency of historical legacy and practice (Krücken 2003), is slow, unable or unwilling to change, the universities will struggle to adapt, and their ability to

\footnotetext{
${ }^{1}$ This article refers only to universities and not to the non-university sector which is made up of 137 institutions in the academies of fine arts, conservatories, dance and theatre schools or other higher education institutions under the jurisdiction of other Ministries.
}

F. Hunter $(\bowtie)$

Centre for Higher Education Internationalisation (CHEI), Università Cattolica del Sacro

Cuore, Milan, Italy

e-mail: fionajanehunter@gmail.com

(C) The Author(s) 2015

A. Curaj et al. (eds.), The European Higher Education Area,

DOI 10.1007/978-3-319-20877-0_7 
interpret and respond to a more international and increasingly competitive environment will depend significantly on their own historical legacy and historically developed practices and identities. In other words, not all institutions will respond at the same pace or develop the same response.

\section{Systemic Tradition of Central Planning and Uniformity}

A highly centralized and uniform model of higher education, established at the time of Italian unification in the second half of the nineteenth century, has persisted over the decades, despite societal pressures for greater decentralization and diversification since the 1960s. Internal pressure groups have had only minor impact in pushing through reform measures and it has only been through exogenous drivers, expressed principally through the Bologna Process, that any headway in reforming the system has been achieved in recent years. Even this pan-European reform process has encountered strong internal resistance from a powerful and conservative academic community, able to influence political direction and take advantage of the inefficiencies of central planning policies and the often unstable and frequently changing political environment (Boffo 1997; Luberto 2007; Luzzatto 1996; Moscati 1991, 2002; Vaira 2003a, b; Woolf 2003).

The lack of any significant degree of genuine university autonomy and institutional variety has acted as an effective barrier to change by removing any 'institutional space' for bottom-up innovation or experimentation (Luberto 2007). Tertiary education has traditionally been provided almost exclusively by universities and, until the Bologna Process reforms, the dominant qualification was the one tier, long cycle, traditional academic degree known as "laurea", with an official length of four to six years. However, actual duration was significantly longer and wastage rates were extremely high, with over $60 \%$ of students failing to complete their studies and often less than $10 \%$ managing to complete within the official timeframe.

Furthermore, university degrees are awarded "valore legale" (legal validity) by the Ministry (MIUR), which exercises control over curricular content, credit weighting and academic ratios in order to ensure homogeneity of standards. Consequently, Italian universities have tended to interpret accountability to the Ministry in the legal and administrative sense of fulfilling requirements, and have, to a large extent, remained isolated from changes in their environment and the needs of external stakeholders (Capano 1998; Luzzatto and Moscati 2007).

Where reforms for greater diversification and decentralization were introduced, the universities' approach was often one of compliance, leading to cosmetic change rather than any significant shift in the traditional structure and culture of the institutions (Meyer and Rowan 1977). This behaviour has been apparent also in the implementation of the Bologna reforms. 


\section{Italian Higher Education Response to the Bologna Process}

Italy acted uncharacteristically as a "first mover", and a landmark reform to redefine the Italian Higher Education landscape according to the Bologna principles was brought into force in 1999. Its objectives were clear: extend institutional autonomy and introduce a Bologna-compatible degree structure, credit system and quality assurance system. The expected outcomes were greater efficiency through increased enrolments and reduced wastage rates, enhanced graduate employability and improved access to the European Labour Market (Guerzoni 2001; Luzzatto and Moscati 2007).

In 2001, the reform swept away the traditional "laurea" replacing it with the "three plus two" structure ("laurea" and "laurea magistrale") and also introduced one-year Professional Masters, accredited directly by the universities, to facilitate access to the labour market. A fully compatible ECTS credit system was introduced to promote a more student-centred approach in curricular design, as well as to encourage student mobility and foster the development of lifelong learning opportunities. The first-ever national evaluation system, coordinated by a national committee with local university units, was established.

However, despite the far-reaching changes in tools and structures and the granting of institutional autonomy, centralization continued with the Ministry retaining significant control over content and severely limiting institutional discretion to characterize programmes (Luzzatto and Moscati 2007; Moscati 2002). Compression and fragmentation often characterized the new degrees, where the academic tendency was often to compress the old four-year degrees into a three-year program and then fragment into many modules. Interaction with employers to design new courses in line with labour market needs was limited principally to those disciplines that already enjoyed a tradition of interaction with external stakeholders.

Compression and fragmentation were often accompanied by proliferation with a doubling in the number of degrees, a burgeoning of branch campuses and new universities, and an increase in the number of academic positions in conditions of a stable or declining student population (CNSVU 2008). Despite an initial rise in student numbers, enrolment levels stabilized and then began to decline. Completion times and wastage rates that seemed to be improving in the early years of the reform slowly slipped back to pre-reform levels. The only constant upward trend appeared to be in the numbers of institutions and programmes that continued to offer a model of "more of the same", rather than any genuine diversification or innovation in institutional profiles or portfolios.

These outcomes suggest that many institutional responses to the reform were made more according to the traditional logic of academic interest, rather than any attempt at interpreting the spirit of the reform and opening up to a European Higher Education space (Luberto 2007; Luzzatto and Moscati 2007). The newly reformed higher education system still suffered from a lack of effective accountability able to 
influence institutional behaviour, and the quality assurance system introduced under the reform package acted more as a data collector, devoid of any tools to assess and reward university performance (Perrotti 2002; Vaira 2003b).

Since the end of the first decade of the Bologna Process, and against a backdrop of political instability and economic decline, successive governments have intervened with several 'reforms of the reform' in an attempt to correct the distortions. Restrictions on content were relaxed in favour of greater institutional discretion, but credit requirements and academic ratios were tightened in an attempt to control proliferation. As a result, the number of courses fell by around a third, bringing bachelors and masters level degree courses down from 5879 to around 1200, and doctoral programmes from 2200 to 919 (ANVUR 2014).

With receding finances, the trend has been one of budget restrictions, but also one of tighter coupling between state expectations and institutional outcomes, along with the introduction of an element of domestic competition. Funding is increasingly linked to performance in an attempt to reward quality and efficiency in teaching and research, although this still has little impact overall. The number of new academic positions has been cut back significantly, but universities who perform well can hire more staff, while those universities that overspend their annual budget are subject to a hiring freeze.

Reforms have sought to further extend institutional autonomy and modernize governance in an attempt to make a radical shift away from a traditional inward-looking model typically centred on disciplinary rather than institutional interests and with very limited external representation, to one that is more agile outward-facing and responsive to stakeholder needs (ANVUR 2014; Boffo 1997; Stefani 2014). Transition towards a more autonomous model of quality assurance in line with European guidelines was completed with the setting up of the National Agency for the Evaluation of Universities and Research (ANVUR) in 2012.

However, after more than almost a decade and a half of legislative attempts to improve the system and align it with European models of practice, recent results appear disheartening. Although in the period between 1993 and 2012, Italy has increased its graduate population in the 25-34 year-old age group from 7.1 to $22.3 \%$ (from 5.5 to $12.7 \%$ of overall population), it is still one of the European countries with the lowest proportion of university graduates (ANVUR 2014). Moreover, the latest figures show that in 2014 the Italian university is losing its appeal with enrolments down $20 \%$ since the introduction of the Bologna reforms. Only three in ten of 19-year olds choose to enrol in a university, making it practically impossible for Italy to reach the European 2020 objective of $40 \%$ of graduates in the 30-34 year old age group (Bartolini 2014a). Indeed, the target has been reset at around 27-28 \% (Cammelli and Gasperoni 2014). Tertiary attainment rates in Italy among 25-34-year olds in 2012 were the fourth lowest in the OECD and G20 countries, ranking 34th out of 37 countries (OECD Reports 2014).

The decision not to enrol at a university may also be linked to low expectations of employment opportunity, but also the time spent in university in order to complete an education. The average time to finish a three-year Bachelor degree is 5.1 years, $70 \%$ more than the official length and 2.8 years for a two-year Master. 
Only one third of Bachelor students and $40 \%$ of Masters students finish in the required time (ANVUR 2014). Overall, dropout rates have improved somewhat, but are still high with 55 out of 100 students completing their studies against an average of 70 in Europe (ANVUR 2014; Bartoloni 2014a, 29th May; Cammelli and Gasperoni 2014). Such disaffection is leading a growing number of Italians to seek their university education abroad. Around 63,000 students enrolled outside Italy in 2011, which was a 51.2\% increase on the numbers in 2006 (Marino 2014).

Those who do complete their studies are inevitably older than their European counterparts: Bachelor graduates are on average 25.5 years old and Master graduates 27.8 , and in the current economic climate many are forced, rather than choose, to seek employment in the European Labour Market because of lack of opportunity at home (Bartoloni 2014a). Between 2008 and 2012, unemployment rates rose steeply and the proportion of 15-29 year olds neither employed nor in education or training (NEET) rose from 19.2 to $24.6 \%$, with only Spain and Turkey faring worse (OECD Reports 2014). The future looks decidedly bleak for many young Italians and far from the promised scenario of the Bologna reforms of the previous decade.

While there are strong regional differences, with Northern Italy generally performing better than the Centre and South (ANVUR 2014), it becomes apparent that despite the many attempts to modernize Italian higher education by successive governments over the last 15 years, structural dysfunctions still hamper any real change within the system. Centralized control based on legal homogeneity of qualifications has created a cumbersome model that makes the shift to the proposed model of the European Higher Education Area a slow and laborious one (Luberto 2007; Neave 1998). The Italian state promotes autonomy and diversity in its reform measures, but imposes regulations that encourage uniformity and rigidity, while the universities have typically resisted top-down reforms and appeared unable or unwilling to generate any bottom-up change from within.

\section{Internationalisation as a Lever for Change}

The data suggest that neither the state nor the institutions have been able to place the context of the reform beyond their own borders and embrace an agenda for change within the emerging European Higher Education Area (Berlinguer 2008). It would also appear that in the subsequent years of financial reduction, the universities have been forced to contain rather than expand or diversify their portfolios and operations. But do these data tell the full story? Or does an examination of internationalization policies and activities provide indications that change is indeed taking place, albeit to varying degrees and at varying rates across the system?

While Italy has always been an active and engaged participant in European programmes for higher education and in Erasmus in particular, the Bologna Process paved the way for new and more diverse forms of internationalization. Alongside the adoption of the specific action lines, the Italian Government introduced a 
number of specific measures to further enhance mobility and internationalization of the curriculum and research, and these have been increasingly embedded in successive legislation for modernization of the higher education system and in each round of the three-year planning cycles for university development.

In the early years of the Bologna Process, legislation was introduced to enable Italian universities to enter agreements for the development and delivery of double and joint degrees, and this legislation was supported by three rounds of successive funding to encourage their realization and support mobility of students and staff. In applying for this special funding, universities were required for the first time to declare their strategic objectives for internationalization.

The program had a very strong uptake across the sector, with universities developing double and joint degrees at masters and doctoral level, and creating a robust foundation for participation in the European Erasmus Mundus program. In addition to the existing 138 Erasmus Mundus Joint Masters in which Italian universities participate, 9 new Joint Masters have been awarded under the first Erasmus Plus call (Erasmus Mundus 2014).

Successive programmes for internationalization have also encouraged the development of academic programmes taught in English, aimed at attracting international students and promoting international research collaboration. There are now 187 degree programmes offered in English that are formally recognized by the Ministry and offered at all levels, from bachelors to doctoral studies, spanning an increasingly broad range of studies from business and engineering to architecture, design, sciences, medicine and even humanities and law.

These initiatives, alongside support from bilateral agreements with a number of countries, including China, have increased the international degree-seeking student population at Italian universities, although the numbers are still low in comparison to other European countries. Italian market share was up from $1.2 \%$ in 2000 to $1.8 \%$ in 2009, with the Marco Polo Program for Chinese Students increasing from 74 students in 2003 to 5269 in 2011 (OBHE 2012). Italy clearly has potential as a country destination, as testified by the growing number of U.S. branch campuses (41 in 2012) that offer study abroad or even full degree programmes such as John Hopkins University in Bologna and John Cabot University in Rome (Caruso and de Wit 2013).

The objectives for the 2013-2015 period also offer, for the first time, the opportunity to internationalize the academic community by encouraging longer-term academic exchange in double and joint degree programmes, as well as short-term teaching contracts for renowned international academics and scholars in standard academic degree programmes (Bruno 2014, 31st January). This initiative has the potential to inject significant innovation into the system, given that currently $99 \%$ of the academic community is Italian (ANVUR 2014).

As performance measurement becomes increasingly important in teaching, research and academic hiring, internationalization also becomes an important indicator. The new criteria for 2014 indicate that one third of funds will be assigned based on merit, according to the ANVUR evaluation, and these will include indicators of Erasmus mobility for both incoming and outgoing students (Bartoloni 
2014b, 11th September). Universities are now being required to internationalize in order to receive funding, rather than being funded in order to internationalize.

Although there is no overarching national strategy for internationalization, it continues to take on greater importance, and this is reflected in the current government's efforts to develop a new set of reform measures for "la buona università" (the good university), aimed at correcting distortions, rewarding performance and opening up the system in order to enable Italy to catch up and align with the Europe 2020 strategy.

While internationalization is emerging increasingly as a key pathway for change and improvement, it should however be noted that reforms are being carried out with a reduced budget for higher education. Italy ranks 5th last in the OECD tables for public spending in education, and is the only country where real public expenditure on educational institutions fell between 2000 and 2011 (OECD Reports 2014).

Interestingly, while public sources fell from 94 to $89 \%$, the share of total funding for schools and universities from private sources almost doubled, with one third of total income now privately generated (OECD Reports 2014). While tuition fees have always been the principal income stream for non-state universities, they are now a significant source of funding for state universities as well. It can be argued that there is an increasing blurring of the divide between public and private higher education in Italy, and the emergence of dual accountabilities to both state and market. Internationalisation is accompanied by the phenomenon of privatization.

\section{Institutional Responses}

How are the universities responding to these increased pressures to internationalize? The first ANVUR report published in 2014 captured only limited internationalization, data but in a 2012 Bologna Experts Seminar on "Rethinking Internationalisation", results were presented from a survey on internationalization strategies at Italian universities. While the survey highlighted that the majority of the universities tended to develop short-term strategies with quantitative goals based on the three-year planning cycles, there were others that set longer strategic timeframes with a more qualitative approach that would enable them to profile and position themselves internationally.

Mobility remained the principal focus and objectives were integrating recognized mobility periods into the curriculum (92\%), international placements (83\%), international research experience $(75 \%)$ and intensive programmes $(64 \%)$. However, the focus on the curriculum across the three levels was also strong with efforts to develop courses in English (78 \%), typically in collaboration with international universities or companies $(72 \%)$. The majority of universities $(85 \%)$ declared that they were developing mechanisms to recruit students internationally, such as offering scholarships and discounted fees, and developing specific support services and communication strategies. Internationalisation of the academic 
community was also indicated by many as a priority through visiting professors (69 \%), recruitment of international academics, including Italians working abroad (64\%), but also by encouraging more outward short-term mobility (50\%).

Equally strong was the focus on enhancing research through international partnerships $(67 \%)$ and funding $(72 \%)$. Universities also recognized the need to upskill professional knowledge across the university and, in particular, improvement of language competences (69\%). A smaller number had set objectives to improve support services (19\%) and build their strategic management capacity (14\%), while a significant percentage planned participation in international higher education management projects (44\%).

Indeed, co-operation was a strong element in many objectives for knowledge exchange $(64 \%)$ and promotion $(50 \%)$. However, the focus appeared to be on bilateral relationships, since few declared a focus on networks $(11 \%)$ and even fewer expressed the intention to develop regional engagement $(5 \%)$. Although $54 \%$ indicated that they did not make use of any international consultancy or professional development services, a smaller group indicated that they had or planned to do so.

The survey revealed very diverse responses in how universities benchmark their international efforts. Both national and international rankings received a $10 \%$ response rate. However, while only $10 \%$ said they benchmarked themselves against other Italian universities, $22 \%$ said they benchmarked against international universities in general and $12 \%$ against similar international universities. A further $20 \%$ indicated associations and networks and $17 \%$ declared the ministerial indicators. Interestingly, $22 \%$ did not answer the question. Italy does not currently fare well in international rankings, but a small number of its universities do manage to appear in the top 200 lists (Bartoloni 2014c, 16th September).

It is true that the survey on internationalization strategies indicates only objectives and not outputs or outcomes, but it does suggest that universities are increasing and diversifying their international efforts. While one third responded that they developed these efforts in response to national legislation, a further third indicated that their strategies go beyond ministerial requirements. This level of change suggests that a number of other changes are taking place within the institutions in order to meet their strategic goals.

Although teaching in English does not necessarily lead to an internationalized curriculum, the increase in the number of these programmes, offered either by the university on its own or in partnership with other institutions, suggests that a certain degree of curricular innovation is taking place. Enhancing exchange programmes or recruiting students internationally means classroom composition and dynamics are being altered. Efforts to internationalize the academic community will inevitably impact to some degree the tradition of a monocultural environment. Some universities may be in a position to exploit international academic labour markets in their search to attract the best possible talent through competitive salaries, while others may be exploiting co-operation agreements and developing creative solutions for longer-term staff exchanges and enhancement of international programmes and projects. 
This would then suggest that new types of partnerships and alliances are emerging, that are stronger and more strategic to institutional goals. While for the majority this means integrated curricula such as double and joint degrees or collaborative short programmes, a small number of universities are spearheading a trend of setting up international operations or even launching branch campuses outside of Italy, often in collaboration with local institutions (OBHE 2012).

Internationalisation exposes and magnifies institutional weaknesses, and one way to overcome this is greater awareness of international practices. While for some universities this means seeking to enter the rankings by aligning with international standards and performance indicators, there is evidence that an increasing number of universities are using their partnerships and networks as a means to benchmark their current practice and improve the quality of their education and research.

Those institutions that are financially well-endowed have also been engaging in (at times major) physical plant investment to ensure their infrastructure meets international expectations, while others focus more on improvement of student services and international competences of academic and administrative staff, such as being able to communicate efficiently in English in an international environment.

While much of the focus of internationalization has been traditionally placed on enhancing academic prestige and positioning, new ventures in education, such as the setting up of international operations or the multiplication of summer schools and development of international recruitment initiatives, suggest that there is now a stronger economic rationale to enhance income generation and diversify the funding base.

In some universities there are also signs that internationalization efforts are linked to a re-aligning of governance structures to encourage more agile processes and break the patterns of traditional academic behaviour tending towards self-referential and change-averse patterns of decision making. While still apparently limited in scale, there is greater use being made of international expertise for environmental and institutional analysis in order to better inform the internationalization strategies and accelerate institutional learning.

So the survey results suggest that Italian universities are (at last) becoming more international as they choose to align with international standards in education and research; teaching in English, recruiting international staff and students, enhancing their international research profile; adopting international practices for academic recruitment, benchmarking against international universities and seeking to position themselves in international rankings.

As they engage in these activities, there are signs that the universities are beginning to develop entrepreneurial capacity as they reach out to new partnerships for new forms of co-operation and income generation, and encourage academic innovation. They are beginning to become more professional as they develop systems and processes that support their strategic direction and institutional goals, and adopt more sophisticated tools to measure their achievements in education and research. 
In other words, Italian universities are changing and internationalization appears to be the lever for that change. They respond to national legislation, but it would appear also increasingly to market demand. The response to the competitive pressures of the new higher education environment is identified in internationalization, but in a manner that requires universities to develop a more adaptive and entrepreneurial mode of behaviour (Davies 1987, 2001; Shattock 2003; Sporn 1999). It requires a new set of competences, structures, tools and processes as well as cultural change. The new globalized environment is creating a shift in the higher education paradigm and is forcing universities to make fundamental changes in the way they operate. They begin to adopt new values and practices in order to adapt to a rapidly evolving context.

\section{Patterns of Convergence and Divergence}

As the Italian state and its universities begin to converge with international models, they diverge from the traditional model and break away from their own historical pathways. As a number of universities engage in increasingly ambitious strategies for internationalization, it appears that a degree of diversification within a highly centralized and uniform system is now taking place. This is in line with the logic of the Bologna Process that has led to structural reform to strengthen compatibility and comparability of qualifications, but at the same time calls for greater institutional diversity and encourages a more competitive environment (Nokkala 2007).

Not all universities will adapt to the requirements of the 21 st century university in the same manner. Some universities may nurture the ambition to become globally positioned, ranked and accredited in order to position themselves at the forefront of their field, while others may choose to play a national or regional role. All are operating in the same national environment but their different trajectories, stages of maturity, geographic locations, regional environments, configurations of academic disciplines, key leadership figures and stakeholders will define their willingness and capacity to respond, whether to ensure educational excellence or simply to guarantee survival.

Figure 1 illustrates different interplays of internal and external conditions, and shows how some institutions respond more rapidly and intuitively to change, while others may be slower to react or even adopt a position of persistence. Internal drivers are described as either static (non-adaptive) or dynamic (adaptive), and the external drivers are either stable or turbulent. The continuous line indicates an institutional pathway as a result of a deliberate strategic choice to respond, whereas the broken line represents a pathway resulting from lack of direction and ad hoc decisions resulting in stasis and strategic drift.

If the pre-Bologna phase is considered to be a relatively stable period for Italian universities, in which the majority of universities, both state and non-state, were not required to respond to strong market pressures for change, they can be located in Quadrant C where they could adopt a static stance. However, in the current 


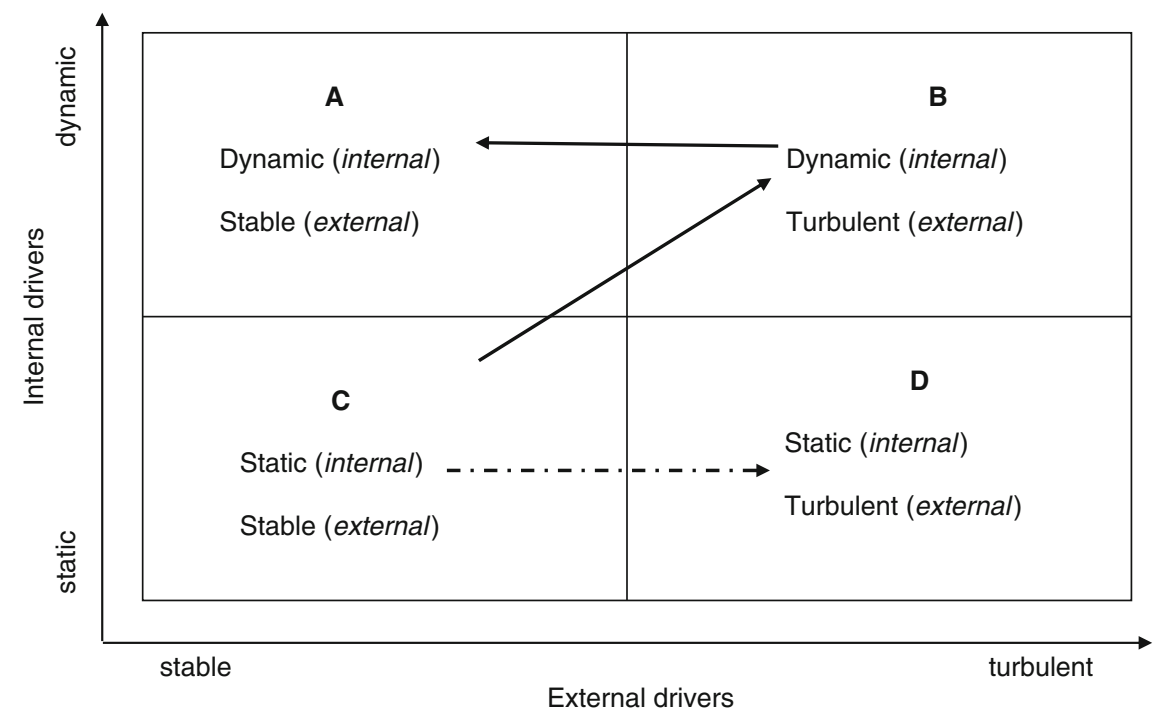

Fig. 1 Interplay of external and internal conditions (Hunter 2009)

turbulent environment, some universities have sensed the need to change and are developing a dynamic response, shifting to Quadrant B. While this is a challenging position for the universities, they will be better placed to take advantage of more stable external conditions in future times, as represented in Quadrant A, provided they continue to develop dynamic internal conditions.

The risk for other universities is that they persist in maintaining their static culture and will be unable to respond rapidly and creatively as the speed of change accelerates, causing them to drift into Quadrant D, the least favourable position of all. A pattern emerges, whereby some universities opt for internationalization in the belief that they have no other choice for institutional survival, while others may be more strongly influenced by state bureaucracy and practice, even though they are aware of the external pressures for change. These contrasting models produce a culture of stasis, since emulation of successful models is not always possible (Carroll 1993).

Internationalization, and the degree of change it implies, may not always be perceived as a desirable choice, but there appear to be an increasing number of Italian universities that recognize it as an inevitable one. As these universities engage in internationalization and look beyond their national borders for future direction, they are lifting themselves out of safe and familiar patterns of operation and measuring themselves against European and international universities in order to define their new identity and ensure their relevance as players, both within and beyond their borders.

A key factor in developing response to competitive pressures is institutional autonomy, reflected in the structures, processes and roles that enable the institution 
to determine its own agenda and strategy. It is what Clark (1998) terms "self-directed autonomy" in contrast to "derived autonomy", as in the Italian case where universities become legally autonomous, but remain constrained by state funding mechanisms that pressure them to follow centrally determined guidelines and limit the available space in which they can develop a unique and innovative strategic response (Clark 1998; Davies 1999, 2001; Shattock 2003; Sporn 1999).

Pressures of external regulations and an unstable political and economic environment operate as powerful constraints to the emergence of institutional autonomy and capacity for innovation and long-term planning in Italy. As market pressures increase, Italian universities will need to be released from the Italian administrative tradition of procedures and rules in order to compete in the European and international higher education arena.

However, even in a constraining legal environment, there is evidence that some universities seek to identify and exploit the opportunities made available to them and that they are developing an "embedded institutional volition" (Clark 2004) for success. Internationalization becomes a natural consequence of that ambition. Indeed, they seek to free themselves from legislative constraints by 'leapfrogging' the national framework and exploiting international trends as a lever for change in their institutions.

\section{Dual Accountability}

Within the Italian higher education model of uniformity and centralization, universities initially had no particular motivation to exploit the autonomy made available to them in the wave of Bologna reforms and behave differently. That pattern has been interrupted by the new higher education conditions and increasing market pressures that are forcing them to adapt, and that adaptation is understood as internationalization. Italian universities are increasingly embarking on strategies for internationalization, not only in response to statutory requirements, but to competitive pressures in the emerging higher education markets at both national and international level.

This would imply that Italian universities are becoming increasingly accountable both to state and market, as they find themselves subject to contrary forces, seeking to meet the demands of their regulatory framework and respond to market pressures. Moreover, it would appear that, for some universities at least, it is the market that is becoming the stronger driver in the new conditions.

Externally-driven change is forcing them to make internal changes, albeit to varying degrees, in an attempt to position themselves in the new European Higher Education Area. The Bologna Process has created a state of flux and it is difficult to imagine that these "frontrunner" universities would have chosen to internationalize without the discontinuity it provided. Exposure to the wider implications of a European Market and competition is taking them in a new direction. 


\section{Isomorphic Tendencies}

The impact of the Bologna Process has awakened international ambition and shifted focus and direction. Many of the changes that are introduced represent path-breaking features. The state and its universities are breaking away from the traditional models to achieve their goals, preferring to emulate international standards and practices. Globalization has been described as a common isomorphic agenda for system decentralization that is producing an anti-isomorphic prescription for institutional diversification (Levy 1999, 2004 Jan). This can lead to a paradox of decreasing diversity between countries and increasing diversity within countries, as universities identify with models beyond their borders.

The powerful commonality of the Bologna process unites European institutions through common practices and structures, while fostering greater organizational diversity and inter-institutional competition in the name of a globally attractive higher education area. It promotes convergence of structures and divergence of response. Structural convergence is increasing competition and requires institutional strategies of diversification for competitive advantage. While a pattern of convergence is emerging at the level of institutional strategy for internationalization, the strategy itself is to be divergent.

\section{Conclusions}

This short article suggests that this paradox is now emerging in Italy, although there is inevitably a certain amount of speculation, given the lack of data on the state of internationalization. As some universities engage in significant international endeavours, they become more nationally diverse, breaking traditional institutional pathways, but at the same time, they become less internationally diverse. They diverge from the national model as they emulate successful international strategies, position themselves internationally and form international partnerships and alliances for competitive advantage.

The Italian State and its higher education institutions have been conditioned by their previous historical accretion of experience and sense of purpose. They have struggled to implement the Bologna reforms and have met with only very limited success until now. International drivers for change however suggest that both the Italian state and an increasing number of universities nurture the ambition to strengthen their strategies and practices in internationalization in order to position themselves as European or international players.

Perhaps, at last, the positions of the state and its more ambitious universities coincide, and no longer on a position of persistence, but rather one of regeneration and revitalization. Change will come in any case to Italian Higher Education. Italy stands at a crossroads, and it is now only a matter of the extent to which Italian 
Higher Education wishes to become an active agent in its own transformation and assert itself in the international arena, or succumb passively to the inevitable consequences of insufficient or slow response.

Open Access This chapter is distributed under the terms of the Creative Commons Attribution Noncommercial License, which permits any noncommercial use, distribution, and reproduction in any medium, provided the original author(s) and source are credited.

\section{References}

ANVUR. (2014). Rapporto sullo stato del sistema universitario e della ricerca 2013: ANVUR.

Bartoloni, M. (2014a, May 29). l'università ai tempi della crisi: si iscrive solo il $30 \%$, calano $i$ fuori corso, l'età media dei laureati è 25 anni Il Sole 24 Ore. Retrieved from www.ilsole24ore. com.

Bartoloni, M. (2014b, September 11). Fondo università, un terzo ripartito in base al "merito" Il Sole 24 Ore. Retrieved from www.ilsole24ore.com.

Bartoloni, M. (2014c, September 16). Bologna unica italiana nella top 200 mondiale Il Sole 24 Ore. Retrieved from www.ilsole24ore.com.

Berlinguer, L. (2008). Nono Profilo dei laureati italiani. In: Consorzio Interuniversitario AlmaLaurea (Ed.), La riforma allo specchio. Bologna: Il Mulino.

Boffo, S. (1997). Evaluation and the distribution of power in Italian Universities. European Journal of Education, 32(2), 175-184.

Bruno, E. (2014, January 31). Più facile lo scambio di docenti e ricercatori con gli atenei stranieri Il Sole 24 Ore. Retrieved from www.ilsole24ore.com.

Cammelli, A., \& Gasperoni, G. (2014). XVI Rapporto AlmaLaurea sul Profilo dei Laureati Italiani Sintesi - Opportunità e sfide dell 'istruzione universitaria in Italia. From www.almalaurea.it.

Capano, G. (1998). La politica universitaria. Bologna: Il Mulino.

Carroll, G. R. (1993). A sociological view on why firms differ. Strategic Management Journal, 14, 237-249.

Caruso, R., \& de Wit, H. (2013). Determinants of inward mobility of students in Europe with a focus on Italy. In Centre for Higher Education Internationalisation (CHEI) (Ed.), An introduction to Higher Education Internationalisatio. Università Cattolica del Sacro Cuore, Milan, Vita e Pensiero.

Clark, B. R. (1998). Creating entrepreneurial universities: Organizational pathways of transformation. Garching: IAU Press.

Clark, B. R. (2004). Sustaining change in universities. New York City: Society for Research into Higher Education and Open University Press.

CNSVU, Comitato nazionale per la valutazione del sistema universitario. (2008). Nono Rapporto sullo Stato del Sistema Universitario Rilevazione Nuclei 2007.

Davies, J. L. (1987). The entrepreneurial and adaptive university. International Journal of Institutional Management of Higher Education, 11(1), 12-104.

Davies, J. L. (1999). Developing a quality culture in European Universities. Paper presented at the CRE-EUA Conference on Quality Audits in Universities, Leuven.

Davies, J. L. (2001). The Emergence of entrepreneurial cultures in European Universities. Paris: OECD.

Erasmus Mundus. (2014). Selezione Joint Master Erasmus Plus: partecipazione italiana. From www.erasmusmundus.it.

Guerzoni, L. (2001). La riforma universitaria in Italia: motivazioni, struttura, risultati attesi. Paper presented at the Conference on Study Reform in Italy and Austria, Bolzano. 
Hunter, F. (2009). Evolutionary sagas of three private universities in Italy: Critical factors in developing institutional responsiveness to exogenous change. Bath: University of Bath.

Krücken, G. (2003). Learning the 'new, new thing': On the role of path dependency in university structures. Higher Education, 46, 315-339.

Levy, D. C. (1999). When private higher education does not bring organizational diversity. In Philip G. Altbach (Ed.), Private prometheus: Private higher education and development in the 21st century. Westport: Greenwood Press.

Levy, D. C. (2004 January). The New Institutionalism: Mismatches with Private Higher Education's Global Growth.

Luberto, G. (2007). In J. Enders \& B. Jongbloed (Eds.), Public-private dynamics in higher education, expectations, developments and outcomes. Bielefeld: Transcript Verlag.

Luzzatto, G. (1996). Higher education in Italy 1985-95: An overview. European Journal of Education, 31(3), 371-378.

Luzzatto, G., \& Moscati, R. (2007). In A. Gornitzka, M. Kogan, \& A. Amaral (Eds.), Reform and change in higher education, analysing policy implementation. CHER: Springer.

Marginson, S. (2007). In J. Enders \& B. Jongbloed (Eds.), Public-private dynamics in higher education, expectations, developments and outcomes. Bielefeld: Transcript Verlag.

Marino, M. L. (2014). Il calo degli immatricolati, in Universitas (No. 133). Retrieved from www. universitas.it.

Meyer, J. W., \& Rowan, B. (1977). Institutionalised organisations: Formal structure as myth and ceremony. The American Journal of Sociology, 83(2), 340-363.

Moscati, R. (1991). In G. Neave \& F. V. Vught (Eds.), Prometheus bound; the changing relationship between government and higher education in Western Europe. Oxford: Pergamon Press.

Moscati, R. (2002). Italy: A hard implementation of a comprehensive reform. Boston College: Winter.

Neave, G. (1998). The evaluative state reconsidered. European Journal of Education, 33(3), 265284.

Nokkala, T. (2007). In J. Enders \& B. Jongbloed (Eds.), Public-private dynamics in higher education, expectations, developments and outcomes. Bielefeld: Transcript Verlag.

OBHE. (2012). Higher Education Reforms and economic crisis in Italy and Spain. Retrieved from www.obhe.ac.uk.

Perrotti, R. (2002). The Italian university system: Rules versus incentives. ISAE Annual Report on Monitoring Italy.

Pfeffer, J., \& Salancik, G. (1978). The external control of organizations: A resource dependence perspective. New York: Harper and Row.

OECD Reports. (2014). Education at a glance 2014. Paris: OECD.

Shattock, M. (2003). Managing successful universities. New York City: Society for Research into Higher Education and Open University Press.

Sporn, B. (1999). Adaptive university structures. London: Jessica Kingsley Publishers Ltd.

Stefani, E. (2014). La legge 240 ha funzionato? In Universitas (No. 133). Retrieved from www. universitas.it.

Vaira, M. (2003a). Riforma universitaria: strategie e leadership.

Vaira, M. (2003b). Higher education reform in Italy: An institutional analysis and a first appraisal 1996-2001.

Van der Wende, M. (2001). Internationalisation policies: About new trends and contrasting paradigms. Higher Education Policy, 14(2), 249-259.

Woolf, S. (2003). On university reform in Italy: Contradictions and power relations in structure and function. Minerva, 41, 347-363. 